\title{
The analysis of the lipid levels in patients with coronary artery disease after percutaneous coronary intervention: a one- year follow-up observational study
}

Weiyu Qiu ${ }^{1+}$, Jiali Chen ${ }^{2+}$, Xianzhen Huang ${ }^{1 *+}$ and Jun Guo ${ }^{1 *+}$

\begin{abstract}
Background: Coronary heart disease (CHD) is one of the leading causes of death worldwide. Percutaneous coronary intervention (PCl) has been an important technology for the treatment of CHD. Blood lipid management is critical for $\mathrm{PCl}$ patients because not only should local vascular pathological changes be considered but the whole atherosclerotic process should be considered as well.

Methods: A total of 522 patients diagnosed with CHD (including acute myocardial infarction and unstable angina) successfully underwent stent implantation in acute or elective $\mathrm{PCl}$ in the cardiology department of one general hospital in Guangzhou from June 2015 to December 2017. The 2016 Chinese Guideline for the Management of dyslipidaemia in Adults and the National Cholesterol Education Program (NCEP) Expert Panel on Detection, Evaluation, and Treatment of High Blood Cholesterol in Adults (Adult Treatment Panel III) final report (NCEP-ATP III) were used to classify total cholesterol (TC), triglyceride (TG), low-density lipoprotein cholesterol (LDL-C) and highdensity lipoprotein cholesterol (HDL-C) levels.

Results: A total of 522 patients were recruited for the study. The mean values of TC, TG, LDL-C, and HDL-C at baseline were 4.76, 1.80, 2.93 and $1.03 \mathrm{mmol} / \mathrm{L}$, respectively. After 1 year of follow-up, the mean values of TC, TG, LDL-C, and HDL-C were 3.94, 1.62, 2.26 and $1.01 \mathrm{mmol} / \mathrm{L}$, respectively. The prevalence of high TC, high TG, high LDL-C and low HDL-C at baseline was 12.05, 21.80, 10.90 and 56.79\%, respectively, and the prevalence at follow-up was 4.59, 15.68, 3.25 and 59.85\%, respectively. Logistic regression revealed that gender was risk factor for high TC ( $\geq$ $6.22 \mathrm{mmol} / \mathrm{L})$, low HDL-C $(<1.04 \mathrm{mmol} / \mathrm{L})$ and high $\mathrm{LDL}-\mathrm{C}(\geq 4.14 \mathrm{mmol} / \mathrm{L})$ at follow-up. Age was the factor associated with high TG $(\geq 2.26 \mathrm{mmol} / \mathrm{L})$ and low HDL-C $(<1.04 \mathrm{mmol} / \mathrm{L})$ at follow-up. Besides, smoking and diet control were risk factors for low HDL-C $(<1.04 \mathrm{mmol} / \mathrm{L})$ and high $\mathrm{LDL}-\mathrm{C}(\geq 4.14 \mathrm{mmol} / \mathrm{L})$ at follow-up, respectively.

(Continued on next page)
\end{abstract}

\footnotetext{
*Correspondence: huangxianzhen926@126.com; dr.guojun@163.com

${ }^{+}$Weiyu Qiu and Jiali Chen contributed equally to this work.

${ }^{+}$Xianzhen Huang and Jun Guo contributed equally to this work.

'Department of Cardiology, The First Affiliated Hospital of Jinan University,

613 Huangpu Da Dao Xi, Guangzhou 510630, Guangdong, China

Full list of author information is available at the end of the article
}

(c) The Author(s). 2020 Open Access This article is licensed under a Creative Commons Attribution 4.0 International License, which permits use, sharing, adaptation, distribution and reproduction in any medium or format, as long as you give appropriate credit to the original author(s) and the source, provide a link to the Creative Commons licence, and indicate if changes were made. The images or other third party material in this article are included in the article's Creative Commons licence, unless indicated otherwise in a credit line to the material. If material is not included in the article's Creative Commons licence and your intended use is not permitted by statutory regulation or exceeds the permitted use, you will need to obtain permission directly from the copyright holder. To view a copy of this licence, visit http://creativecommons.org/licenses/by/4.0/ The Creative Commons Public Domain Dedication waiver (http://creativecommons.org/publicdomain/zero/1.0/) applies to the data made available in this article, unless otherwise stated in a credit line to the data. 
(Continued from previous page)

Conclusion: The patients with PCl at follow-up experienced lower mean values of lipids and prevalence of dyslipidaemia than those at baseline. Gender, age, smoking and diet control were the risk factors associated with elevated lipids. Improvement in lipid management at follow up demonstrated that such intervention can be effective.

Keywords: Serum lipids, Percutaneous coronary intervention, Prevalence, Risk factors, Follow-up, Observational study

\section{Introduction}

Due to urbanization, economic growth and an ageing population, China's disease spectrum has changed. Coronary heart disease (CHD) has become a public health issue and is the leading cause of death globally $[1,2]$. CHD is not only an important cause of death in developed countries but also in developing countries [3]. One of the treatment strategies for $\mathrm{CHD}$ is to relieve severe coronary occlusion, and another strategy is to control risk factors. Although percutaneous coronary intervention (PCI) has been an important technology for the treatment of $\mathrm{CHD}$, it can only cause local vascular pathological changes [4], and the entire atherosclerotic process should be considered. Therefore, postoperative management after PCI is essential.

Abnormal blood lipid metabolism is a risk factor for CHD [5]. The increase in total cholesterol (TC) and low-density lipoprotein cholesterol (LDL-C) and the decrease in high-density lipoprotein cholesterol (HDL-C) levels are the main factors associated with cardiovascular disease [6]. Therefore, blood lipid levels play a crucial role in the development of CHD. Previous studies have shown that TC, LDL-C and triglyceride (TG) levels were increasing $[7,8]$, and hypercholesterolemia was not adequately controlled in Chinese adults aged 35 to 74 years [7]. Meta-analysis results showed that an LDL-C reduction of $1 \mathrm{mmol} / \mathrm{L}$ can effectively reduce the incidence of cardiovascular events [9].

Previous studies on dyslipidaemia have been conducted in individuals with chronic diseases such as hypertension and diabetes [10], obese people [11] and the Chinese general population [7, 12-14]. There are relatively few studies on the management of dyslipidaemia in patients with PCI, and there are even fewer follow-up studies. The following hypothesis was proposed: Follow-up is helpful to control the lipid profiles in PCI patients. Therefore, this study aimed to explore the blood lipid status of patients after PCI through a one-year follow-up period.

\section{Materials and methods}

\section{Subjects}

This retrospective analysis of 522 patients diagnosed with CHD (including acute myocardial infarction and unstable angina) successfully underwent stent implantation in acute or elective PCI in the cardiology department of one general hospital in Guangzhou from June 2015 to December 2017.

The sample size estimation was calculated using the following formula: $n=\left[z_{\alpha} \sqrt{2 \overline{p q}}+z_{\beta} \sqrt{p_{0} q_{0}+p_{1} q_{1}}\right]^{2} /$ $\left(p_{1}-p_{0}\right)^{2}$, where $\mathrm{Z} \alpha=1.96 ; \mathrm{Z}_{\beta}=1.282 ; \mathrm{p}_{0}=0.081 ; \mathrm{q}_{0}=1$ $\mathrm{p}_{0}=0.919 ; \mathrm{p}_{1}=\mathrm{RR} * \mathrm{p}_{0}=2.5 * 0.081=0.203 ; \mathrm{q}_{1}=1-$ $\mathrm{p}_{1}=0.797 ; \bar{p}=\mathrm{p}_{0}+\mathrm{p}_{1} / 2=0.142 ;$ and $\bar{q}=1-\bar{p}=0.858$. According to the formula, the sample size was estimated to be 169 subjects with a $10 \%$ loss to follow-up; therefore, the number of patients included in the study was 186 .

\section{Study procedure}

This study was conducted by a case manager. Because it is typical for patients who undergo PCI to stay in the cardiac intensive care unit (CCU) for one night, health education (focused on medication guidance, lifestyle, and follow up) for patients was first conducted by CCU nurses, and then the next day upon transfer to the general ward, the nurses in the general ward continued providing education to the patients. The case manager registered the patients' information and created a follow-up form. For the patients included in 2015 and 2016, the case manager followed up the patients discharged from the hospital after 1 year by telephone, gathering data including information on chest pain, medicine, follow-up, lifestyle, cardiac function. For patients in 2017, telephone follow-up was performed at 1 month, 3 months, 6 months and 1 year after discharge, and data were collected including information on medication, discomfort, complications, follow-up, lipids, colour Doppler sonography results and lifestyle. Patients in 2015 and 2016 were verbally informed about the follow-up procedure. Patients in 2017 were informed about a follow-up plan after which they provided written informed consent. To control the bias, the case manager was responsible for the whole process of recording the information in the database and the follow-up plan.

\section{Study parameters}

The data were collected from medical records and faceto-face or telephone interviews. The information included demographic characteristics (name, gender, age, ethnicity, telephone number, residence, education, marital status, 
occupation, family monthly income), medical history (hypertension, diabetes, CHD, stroke and dyslipidaemia), lifestyle and self-management (diet control, daily staple food intake, regular exercise, weekly exercise time, smoking and drinking history), physical examination (height, weight), and laboratory examination (blood lipids at baseline and follow-up). The lipids were obtained in the morning after an overnight fast. TC (enzymatic method), TG (enzymatic method), HDL-C (direct method), and LDL-C (direct method) levels were measured.

\section{Definition}

The 2016 Chinese Guidelines for the Management of Dyslipidaemia in Adults were used to classify TC, TG, LDL-C and HDL-C levels [15]. The classification was based on the criteria in the Third Report of the National Cholesterol Education Program (NCEP) Expert Panel on Detection, Evaluation, and Treatment of High Blood Cholesterol in Adults (Adult Treatment Panel III) final report (NCEP-ATP III) [16]. The diagnostic criteria of diabetes mellitus (DM) were based on the 1999 WHO diagnostic criteria [17]. DM was defined as fasting plasma glucose (FPG) $\geq 7.0 \mathrm{mmol} / \mathrm{L}$, 2-h postprandial plasma glucose $(2 \mathrm{hPG}) \geq 11.1 \mathrm{mmol} / \mathrm{L}$, or diabetic symptoms along with a random plasma glucose level $\geq 11.1$ $\mathrm{mmol} / \mathrm{L}$. Hypertension was defined as systolic blood pressure $(\mathrm{SBP}) \geq 140 \mathrm{mmHg}$ and/or diastolic blood pressure (DBP) $\geq 90 \mathrm{mmHg}$. High TC was defined as TC $\geq$ $6.22 \mathrm{mmol} / \mathrm{L}$. High LDL-C was defined as LDL-C $\geq 4.14$ $\mathrm{mmol} / \mathrm{L}$, low HDL-C was defined as $\mathrm{HDL}-\mathrm{C}<1.04$ $\mathrm{mmol} / \mathrm{L}$, and high TG were defined as $\geq 2.26 \mathrm{mmol} / \mathrm{L}$. Based on the status of self-reported smoking and the definition of the global adult tobacco survey [18], individuals were categorized into three groups: never, former and current smokers. Respondents were asked whether they had a drink over the past year. According to the adult weight standard published by the Ministry of Health of China, body mass index $(\mathrm{BMI})<18.5 \mathrm{~kg} / \mathrm{m}^{2}$ indicated low weight, $18.5 \mathrm{~kg} / \mathrm{m}^{2} \leq \mathrm{BMI}<24 \mathrm{~kg} / \mathrm{m}^{2}$ indicated normal weight, $24 \mathrm{~kg} / \mathrm{m}^{2} \leq \mathrm{BMI}<28 \mathrm{~kg} / \mathrm{m}^{2}$ indicated overweight and $\mathrm{BMI} \geq 28 \mathrm{~kg} / \mathrm{m}^{2}$ indicated obesity. Light physical activity referred to sitting, standing or walking, and activities not requiring special muscular function, such as reading, writing, performing office work, assembling and repairing machines, lecturing, performing general laboratory operations, doing housework. Moderate physical activity referred to activities with greater muscular requirements, such as performing daily activities of students, driving motor vehicles, installing electrical components, cutting metal, performing woodworking operations. Heavy physical activity referred to nonmechanized agricultural labour, steelmaking, lathe operation, sports activities (swimming, mountain climbing, football). Regular exercise was defined as exercising at least 3 times a week for at least 30 mins at a time.

\section{Data analysis}

All data were analysed using SPSS version 13.0 software. Quantitative data were expressed as the means \pm SD. Categorical variables were estimated as frequencies. The comparisons of quantitative data were conducted using the independent samples $t$-test, and categorical variables were compared using the chi-square test. The comparison between lipid profiles at baseline and follow-up was performed using a paired $t$ test. Binary logistic regression analysis was used to assess the risk factors. Odds ratios (ORs) with 95\% confidence intervals (95\%CIs) were expressed. $P<0.05$ was considered statistically significant.

\section{Results}

\section{Demographic and clinical features of patients}

Figure 1 shows the flowchart of participants analysed in the study. A total of 522 patients aged $28-88$ years (63.15 \pm 11.38 years), including 393 males $(75.3 \%)$ and 129 females (24.7\%), were enrolled in the study. According to the LDL-C levels at baseline, patients

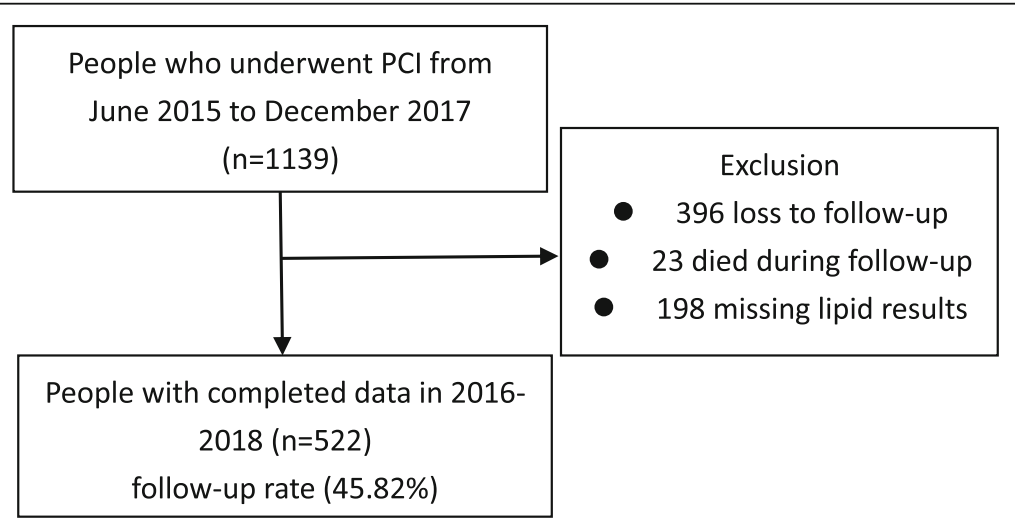

Fig. 1 Flow diagram of patients analysed in the study 
Table 1 Characteristics of the patients according to the LDL levels at baseline

\begin{tabular}{|c|c|c|c|c|c|c|c|}
\hline \multirow[t]{2}{*}{ Characteristics } & \multicolumn{7}{|c|}{ LDL-C levels } \\
\hline & $<2.59$ & $2.59-<3.37$ & $3.37-<4.14$ & $4.14-<4.92$ & $\geq 4.92$ & $x^{2}$ & $P$-value \\
\hline \multicolumn{6}{|l|}{ Age (years), n(\%) } & 29.793 & 0.073 \\
\hline $28-29$ & $0(0.0)$ & $0(0.0)$ & $1(100.0)$ & $0(0.0)$ & $0(0.0)$ & & \\
\hline $30-39$ & $5(38.5)$ & $4(30.8)$ & $2(15.4)$ & $2(15.4)$ & $0(0.0)$ & & \\
\hline $40-49$ & $14(29.2)$ & $9(18.8)$ & $18(37.5)$ & $5(10.4)$ & $2(4.2)$ & & \\
\hline $50-59$ & $41(30.4)$ & $42(31.1)$ & $39(28.9)$ & $9(6.7)$ & $4(3.0)$ & & \\
\hline $60-69$ & $71(44.7)$ & $39(24.5)$ & $31(19.5)$ & $16(10.1)$ & $2(1.3)$ & & \\
\hline$\geq 70(\%)$ & $76(45.8)$ & $48(28.9)$ & $25(15.1)$ & $12(7.2)$ & $5(3.0)$ & & \\
\hline \multicolumn{6}{|l|}{ Gender, n(\%) } & 0.637 & 0.959 \\
\hline Male & $156(39.7)$ & $108(27.5)$ & $88(22.4)$ & $31(7.9)$ & $10(2.5)$ & & \\
\hline Female & $51(39.5)$ & $34(26.4)$ & $28(21.7)$ & $13(10.1)$ & $3(2.3)$ & & \\
\hline \multicolumn{6}{|l|}{ BMI $\left(\mathrm{kg} / \mathrm{m}^{2}\right), \mathrm{n}(\%)$} & 11.543 & 0.483 \\
\hline$<18.5$ & $4(36.4)$ & $3(27.3)$ & $3(27.3)$ & $0(0.0)$ & $1(9.1)$ & & \\
\hline $18.5-<24.0$ & $110(41.5)$ & $75(28.3)$ & $53(20.0)$ & $23(8.7)$ & $4(1.5)$ & & \\
\hline $24.0-<28.0$ & $68(38.0)$ & $50(27.9)$ & $38(21.2)$ & $16(8.9)$ & $7(3.9)$ & & \\
\hline$\geq 28.0$ & $25(37.3)$ & $14(20.9)$ & $22(32.8)$ & $5(7.9)$ & $1(1.5)$ & & \\
\hline \multicolumn{6}{|l|}{ Education, n(\%) } & 5.006 & 0.958 \\
\hline Primary school & $32(42.7)$ & 19 (25.3) & 15 (20.0) & $7(9.3)$ & $2(2.7)$ & & \\
\hline Middle school & $82(38.5)$ & $58(27.2)$ & $51(23.9)$ & $16(7.5)$ & $6(2.8)$ & & \\
\hline High school & $81(40.1)$ & $53(26.2)$ & $43(21.3)$ & $20(9.9)$ & $5(2.5)$ & & \\
\hline$>$ High school & $12(37.5)$ & $12(37.5)$ & 7 (21.9) & $1(3.1)$ & $0(0.0)$ & & \\
\hline \multicolumn{6}{|l|}{ Residence, n(\%) } & 0.267 & 0.992 \\
\hline Urban & $132(40.4)$ & $88(26.9)$ & $71(21.7)$ & $28(8.6)$ & $8(2.4)$ & & \\
\hline Rural & 75 (38.5) & $54(27.7)$ & $45(23.1)$ & $16(8.2)$ & $5(2.6)$ & & \\
\hline \multicolumn{6}{|l|}{ Smoking, n(\%) } & 12.097 & 0.147 \\
\hline Never & $131(43.2)$ & $78(25.7)$ & $65(21.5)$ & $22(7.3)$ & $7(2.3)$ & & \\
\hline Former & $22(50.0)$ & $11(25.0)$ & 6 (13.6) & $3(6.8)$ & $2(4.5)$ & & \\
\hline Current & $54(31.0)$ & $53(30.5)$ & $45(25.9)$ & 19 (10.9) & $3(1.7)$ & & \\
\hline \multicolumn{6}{|l|}{ Drinking, n(\%) } & 4.553 & 0.336 \\
\hline Yes & $23(39.0)$ & $11(18.6)$ & $16(27.1)$ & $6(10.2)$ & $3(5.1)$ & & \\
\hline No & 184 (39.7) & 131 (28.3) & 100 (21.6) & $38(8.2)$ & $10(2.2)$ & & \\
\hline \multicolumn{6}{|l|}{ Occupation, n(\%) } & 12.719 & 0.122 \\
\hline Light & 179 (41.7) & 115 (26.8) & $93(21.7)$ & $31(7.2)$ & $11(2.6)$ & & \\
\hline Medium & $27(30.3)$ & $24(27.0)$ & $23(25.8)$ & $13(14.6)$ & $2(2.2)$ & & \\
\hline others & $1(25.0)$ & $3(75.0)$ & $0(0.0)$ & $0(0.0)$ & $0(0.0)$ & & \\
\hline \multicolumn{6}{|c|}{ Famliy monthly income per capita, n(\%) } & 9.987 & 0.617 \\
\hline$<1000$ & $0(0.0)$ & $0(0.0)$ & $1(100.0)$ & $0(0.0)$ & $0(0.0)$ & & \\
\hline $1000-3000$ & $58(37.2)$ & $41(26.3)$ & $40(25.6)$ & $13(8.3)$ & $4(2.6)$ & & \\
\hline $3000-6000$ & $135(41.7)$ & $85(26.2)$ & $68(21.0)$ & $29(9.0)$ & $7(2.2)$ & & \\
\hline$>6000$ & $14(34.1)$ & $16(39.0)$ & $7(17.1)$ & $2(4.9)$ & $2(4.9)$ & & \\
\hline \multicolumn{6}{|l|}{ Diet control, n(\%) } & 5.948 & 0.203 \\
\hline No & $39(31.7)$ & $33(26.8)$ & $34(27.6)$ & $13(10.6)$ & $4(3.3)$ & & \\
\hline Yes & $168(42.1)$ & $109(27.3)$ & $82(20.6)$ & $31(7.8)$ & $9(2.3)$ & & \\
\hline \multicolumn{6}{|c|}{ Daily staple food intake, n(\%) } & 12.308 & 0.138 \\
\hline
\end{tabular}


Table 1 Characteristics of the patients according to the LDL levels at baseline (Continued)

\begin{tabular}{|c|c|c|c|c|c|c|c|}
\hline \multirow[t]{2}{*}{ Characteristics } & \multicolumn{7}{|c|}{ LDL-C levels } \\
\hline & $<2.59$ & $2.59-<3.37$ & $3.37-<4.14$ & $4.14-<4.92$ & $\geq 4.92$ & $x^{2}$ & $P$-value \\
\hline Rice & $185(38.8)$ & $128(26.8)$ & $112(23.5)$ & $40(8.4)$ & $12(2.5)$ & & \\
\hline Noodle & $1(14.3)$ & $3(42.9)$ & $1(14.3)$ & $2(28.6)$ & $0(0.0)$ & & \\
\hline Rice+Noodle & $21(55.3)$ & $11(28.9)$ & $3(7.9)$ & $2(5.3)$ & $1(2.6)$ & & \\
\hline Physical activity, n(\%) & & & & & & 6.349 & 0.175 \\
\hline No & $5(20.0)$ & $8(32.0)$ & $8(32.0)$ & $4(16.0)$ & $0(0.0)$ & & \\
\hline Yes & $202(40.6)$ & $134(27.0)$ & $108(21.7)$ & $40(8.0)$ & $13(2.6)$ & & \\
\hline
\end{tabular}

LDL-C low-density lipoprotein cholesterol, BMI body mass index

were divided into five groups: $<2.59 \mathrm{mmol} / \mathrm{L}, 2.59$ $\mathrm{mmol} / \mathrm{L}-<3.37 \mathrm{mmol} / \mathrm{L}, 3.37 \mathrm{mmol} / \mathrm{L}-<4.14 \mathrm{mmol} /$ $\mathrm{L}, \quad 4.14 \mathrm{mmol} / \mathrm{L} \quad-<4.92 \mathrm{mmol} / \mathrm{L}$, and $\geq 4.92 \mathrm{mmol} / \mathrm{L}$. The differences in age, gender, BMI, education, residence, smoking, alcohol consumption, occupation, family monthly income, diet control, daily staple food intake and physical activity were not significant $(P>$ 0.05) (Table 1). In addition, patients were divided into three groups separately based on TC, TG and HDL-C levels at baseline. The differences in TG levels at baseline according to age, BMI, education, drinking and daily staple food intake were significant $(P<0.05)$. Gender, BMI, smoking and alcohol consumption were significantly associated with HDL-C levels at baseline $(P<0.05)$ (Table 2).

The mean values of TC, TG, LDL-C, and HDL-C at baseline were 4.76, 1.80, 2.93 and $1.03 \mathrm{mmol} / \mathrm{L}$, respectively. After 1 year of follow-up, the mean TC, TG, LDL$\mathrm{C}$, and HDL-C levels were 3.94, 1.62, 2.26 and 1.01 $\mathrm{mmol} / \mathrm{L}$, respectively. There was a significant difference in TC, TG and LDL-C levels between baseline and follow-up $(P<0.05)$ (Table 3). The prevalence of high TC, high TG, high LDL-C and low HDL-C at baseline was $12.05,21.80,10.90$ and $56.79 \%$, respectively, and the prevalence at follow-up was 4.59, 15.68, 3.25 and $59.85 \%$, respectively. The difference in prevalence between baseline and follow-up was significant $(P<$ 0.05) (Table 4).

Among 522 patients included in the 1 year follow-up, a total of 484 patients' stents were unobstructed, 1 had reimplantation via PCI, 7 had intimal hyperplasia, 1 died, 7 had stent stenosis, 22 were followed up for blood lipids in the outpatient department, and no patients were hospitalized for vascular examination.

As shown in Table 5, the proportion of patients at follow-up with borderline high $(5.18-<6.22 \mathrm{mmol} / \mathrm{L})$ and high TC levels $(\geq 6.22 \mathrm{mmol} / \mathrm{L})$ was 7.1 and $4.6 \%$, respectively, which was higher among those living in rural areas than urban areas. The proportion of patients at follow-up with borderline high $(1.69-<2.26 \mathrm{mmol} / \mathrm{L})$ and high $(\geq 2.26 \mathrm{mmol} / \mathrm{L})$ TG was 15.7 and $15.7 \%$, respectively, and the proportion was higher in younger patients than in older patients. The proportion of patients at follow-up with low HDL-C was $60.2 \%$, which was much higher in younger patients than in older patients and was higher in men than in women. The proportion of patients at follow-up with borderline high $(3.37-<4.14 \mathrm{mmol} / \mathrm{L})$, high $(4.14-<4.92 \mathrm{mmol} / \mathrm{L})$, and very high ( $\geq 4.92 \mathrm{mmol} / \mathrm{L}) \mathrm{LDL}-\mathrm{C}$ levels was $6.1,2.1$ and $1.1 \%$, respectively. The proportion of patients living in rural areas with borderline high, high and very high LDL-C was significantly higher than that of patients living in urban areas.

Multivariate logistic regression analysis showed that gender was risk factor for high $\mathrm{TC}(\geq 6.22 \mathrm{mmol} / \mathrm{L})$, low HDL-C $(<1.04 \mathrm{mmol} / \mathrm{L})$ and high LDL-C $(\geq 4.14$ $\mathrm{mmol} / \mathrm{L}$ ) at follow-up. Age was the factor associated with high TG $(\geq 2.26 \mathrm{mmol} / \mathrm{L})$ and low HDL-C $(<$ $1.04 \mathrm{mmol} / \mathrm{L}$ ) at follow-up. Besides, smoking and diet control were risk factors for low HDL-C $(<1.04$ $\mathrm{mmol} / \mathrm{L})$ and high LDL-C $(\geq 4.14 \mathrm{mmol} / \mathrm{L})$ at followup, respectively (Table 6).

\section{Discussion}

Blood lipid management after PCI is essential because dyslipidaemia is an important risk factor for CHD. This study was performed by recruiting 522 patients from 2015 to 2017 who had undergone PCI. The results showed that a significant decrease in the mean TC, TG and LDL-C levels was observed between baseline and follow-up. Similarly, a significant decrease in the prevalence of high TC, high TG and high LDL-C was observed over the same period. The mean TC, TG, LDL-C, and HDL-C levels at baseline were 4.76, 1.80, 2.93 , and $1.03 \mathrm{mmol} / \mathrm{L}$, respectively, which were higher than the mean values of lipids in Chinese adults reported in the 1983, 1993 [13], 2013-2014 [12], and 2002 China National Nutrition and Health Survey [14], respectively. This may be related to the information on myocardial infarction reported in this study. The TC and LDL-C levels were significantly lower in this study than the levels in the United States [19] and Japan [20] but 


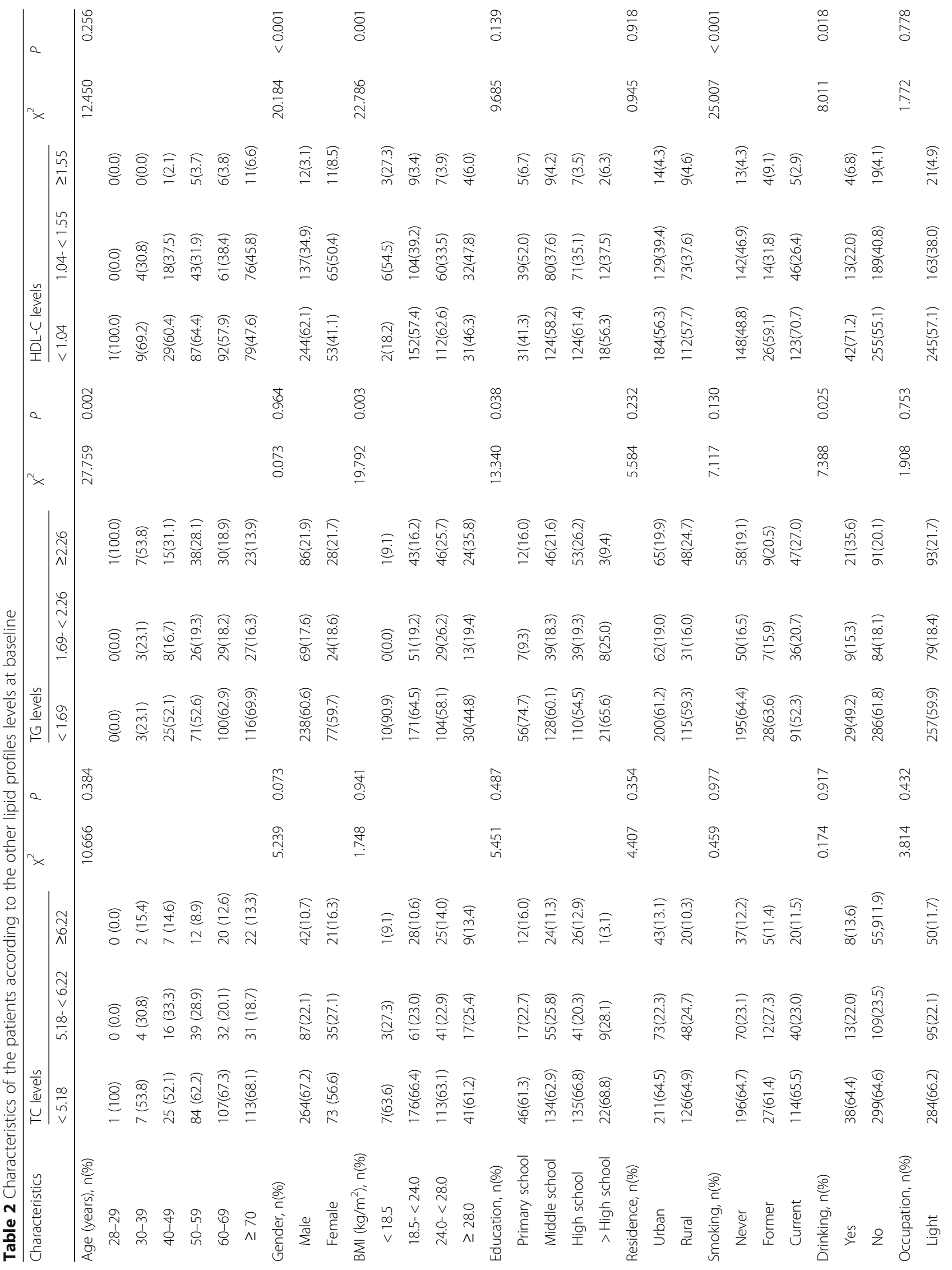




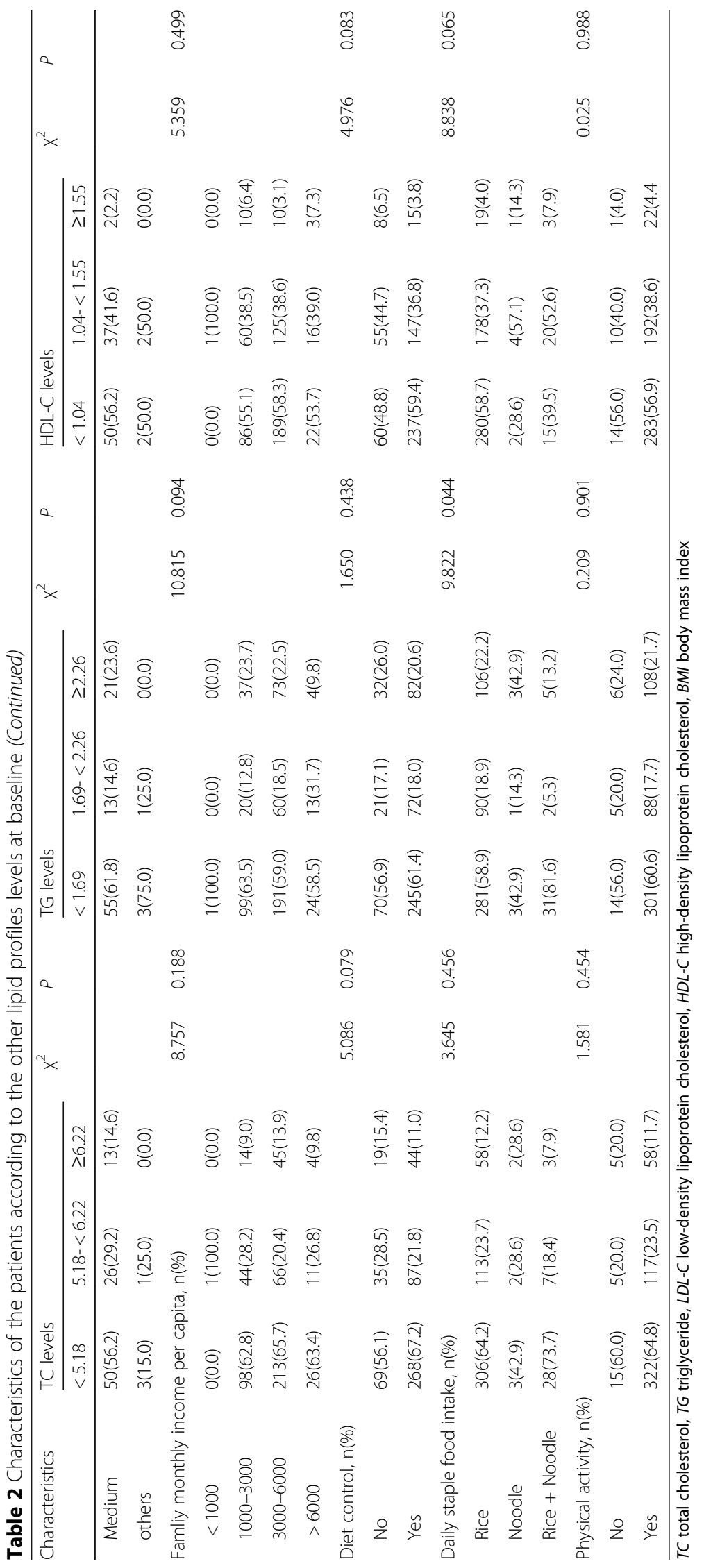


Table 3 The comparison of lipid profiles between baseline and follow-up

\begin{tabular}{lllll}
\hline Characteristics & At baseline & At follow-up & $\mathrm{t}$ & $P$ \\
\hline TC & $4.76 \pm 1.25$ & $3.94 \pm 1.05$ & 11.456 & $<0.001$ \\
TG & $1.80 \pm 1.31$ & $1.62 \pm 1.25$ & 2.256 & 0.024 \\
LDL-C & $2.93 \pm 0.94$ & $2.26 \pm 0.81$ & 12.428 & $<0.001$ \\
HDL-C & $1.03 \pm 0.28$ & $1.01 \pm 0.28$ & 1.082 & 0.279 \\
\hline
\end{tabular}

TC total cholesterol, TG triglyceride, LDL-C low-density lipoprotein cholesterol, $H D L-C$ high-density lipoprotein cholesterol

similar to those in Korea [21]. After 1 year of followup, the patients' TC, TG, LDL-C and HDL-C levels were significantly lower than those at baseline, which indicates that post-discharge follow-up management is essential.

The current study confirmed that the prevalence rates of high TC, high TG, high LDL-C and low HDL-C at baseline were $12.05,21.80,10.90$, and $56.79 \%$, respectively, which were higher than those reported in 2002 [14] and 2013-2014 [12]. This was mainly due to the different populations involved and the different definitions of the indicators. Dyslipidaemia in this population is mainly reflected by lower HDL-C and higher TG, which is consistent with findings in previous studies [12] but different from those in the United States (high TC and high LDL-C) [19], which may be due to differences in diet and genetic susceptibility.

The study suggested that age was the factor associated with high TG and low HDL-C at follow-up. Gender was risk factor for high TC, low HDL-C and high LDL-C at follow-up. Besides, smoking and diet control were risk factors for low HDL-C and high LDL-C at follow-up respectively. Previous studies reported that age appeared to influence dyslipidaemia risk [7, 22, 23]. Similar results were found in this study. The reason for this may be poor compliance with long-term drug treatment, more comorbidities, high economic pressure, failure to buy drugs and difficulty in making lifestyle changes among elderly patients. The mechanism of the effect of age on lipids is not well known. Other research has observed an

Table 4 The comparison of high lipid prevalence between baseline and follow-up

\begin{tabular}{lllll}
\hline Characteristics & \multicolumn{2}{l}{ Prevalence (\%) } & $X^{2}$ & $P$ \\
\cline { 2 - 3 } & At baseline & At follow-up & & \\
\hline High TC & 12.05 & 4.59 & 19.072 & $<0.001$ \\
High TG & 21.80 & 15.68 & 6.432 & 0.011 \\
High LDL-C & 10.90 & 3.25 & 23.271 & $<0.001$ \\
Low HDL-C & 56.79 & 59.85 & 1.220 & 0.269 \\
\hline
\end{tabular}

$T C$ total cholesterol, TG triglyceride, $L D L-C$ low-density lipoprotein cholesterol, $H D L-C$ high-density lipoprotein cholesterol association between dyslipidaemia and gender [7, 22, 23]. This study also showed that gender was related to high TC, low HDL-C and high LDL-C at followup. This may be associated with lifestyle and dietary differences.

A previous study revealed associations between dyslipidaemia and smoking [24]. The results demonstrated that smoking was significantly associated with the risk of low HDL-C at follow-up. Nicotine, caffeine and other substances in tobacco can stimulate blood vessels and cause structural changes, which leads to dyslipidaemia. Moreover, the importance of diet control is evident for the control of blood lipid levels. Besides, due to the $100 \%$ or $99 \%$ would be positive, the daily staple food intake was not be included in the regression analysis when analyzing the LDL-C.

\section{Study strengths and limitations}

The major strength of the study was the inclusion of PCI patients, which provided a representativeness of the findings in PCI management. Standardized survey instruments and a trained interviewer guaranteed the reliability of the analyses. Some limitations of the study deserve to be mentioned. First, the patients included in 2015 and 2016 did not have a detailed follow-up plan, thus follow-up was performed only 1 year after discharge. Second, during the telephone follow-up period, the patients were only verbally asked if their lifestyle and habits had improved; therefore, there was a lack of data registration for changes in lifestyle at follow-up. Third, due to the lack of information on lifestyle changes, it was impossible to discuss the relationship between lipid profiles and lifestyle changes at followup. Fourth, although lipid-lowering medication data existed, the related lifestyle changes were not registered, thus the relationship between lipid profiles at follow-up and lipid-lowering medication could not analysed. Lastly, because of missing information, the comparison between participants who were followed up and participants who were not followed up were not analysed.

\section{Conclusions}

In conclusion, after 1 year of follow-up, the mean values of lipids and the prevalence of dyslipidaemia in patients with PCI at follow-up included in the study were significantly lower than those at baseline. Gender, age, smoking, and diet control affected patients' blood lipids. Therefore, postoperative management of discharged PCI patients is crucial and provides a basis for primary health care. However, a large sample size and long-term follow-up are needed to further explore the associations of lifestyle changes 
Table 5 Proportion of lipid fraction serum levels at follow-up according to Chinese guidelines classification



TC total cholesterol, TG triglyceride, $L D L-C$ low-density lipoprotein cholesterol, HDL-C high-density lipoprotein cholesterol

Table 6 The association between factors at baseline and dyslipidemia at follow-up in a binary logistic regression analyses

\begin{tabular}{|c|c|c|c|c|c|c|c|c|c|c|c|c|}
\hline & \multicolumn{3}{|c|}{$\mathrm{TC} \geq 6.22 \mathrm{mmol} / \mathrm{L}$} & \multicolumn{3}{|c|}{$\mathrm{TG} \geq 2.26 \mathrm{mmol} / \mathrm{L}$} & \multicolumn{3}{|c|}{$\mathrm{HDL}-\mathrm{C}<1.04 \mathrm{mmol} / \mathrm{L}$} & \multicolumn{3}{|c|}{$\mathrm{LDL}-\mathrm{C} \geq 4.14 \mathrm{mmol} / \mathrm{L}$} \\
\hline & $\mathrm{OR}$ & $95 \% \mathrm{Cl}$ & $P$ value & $\mathrm{OR}$ & $95 \% \mathrm{Cl}$ & $P$ value & $\mathrm{OR}$ & $95 \% \mathrm{Cl}$ & $P$ value & $\mathrm{OR}$ & $95 \% \mathrm{Cl}$ & $P$ value \\
\hline Gender & 0.268 & $0.082,0.875$ & 0.029 & 0.915 & $0.471,1.777$ & 0.793 & 2.754 & $1.679,4.517$ & $<0.001$ & 0.153 & $0.034,0.687$ & 0.014 \\
\hline Age & 1.008 & $0.964,1.054$ & 0.734 & 1.030 & $1.005,1.055$ & 0.020 & 1.025 & $1.005,1.045$ & 0.014 & 1.030 & $0.978,1.086$ & 0.261 \\
\hline BMI & 1.011 & $0.868,1.177$ & 0.889 & 1.005 & $0.921,1.097$ & 0.906 & 1.035 & $0.968,1.107$ & 0.318 & 1.196 & $0.989,1.446$ & 0.064 \\
\hline Education & 1.042 & $0.485,2.236$ & 0.917 & 1.032 & $0.670,1.589$ & 0.886 & 1.376 & $0.994,1.906$ & 0.054 & 0.594 & $0.238,1.484$ & 0.265 \\
\hline Residence & 0.522 & $0.195,1.399$ & 0.196 & 0.814 & $0.464,1.427$ & 0.472 & 1.197 & $0.766,1.870$ & 0.429 & 0.352 & $0.107,1.156$ & 0.085 \\
\hline Smoking & 0.690 & $0.387,1.229$ & 0.208 & 1.154 & $0.857,1.554$ & 0.346 & 0.790 & $0.626,0.998$ & 0.048 & 0.806 & $0.389,1.672$ & 0.563 \\
\hline Drinking & 1.627 & $0.464,5.702$ & 0.447 & 1.622 & $0.784,3.355$ & 0.192 & 0.774 & $0.416,1.441$ & 0.419 & 3.643 & $0.945,14.039$ & 0.060 \\
\hline Occupation & 1.115 & $0.373,3.328$ & 0.845 & 1.469 & $0.740,2.917$ & 0.272 & 0.921 & $0.587,1.446$ & 0.721 & 1.260 & $0.348,4.564$ & 0.725 \\
\hline Famliy monthly income per capita & 1.211 & $0.474,3.090$ & 0.689 & 1.166 & $0.680,1.999$ & 0.578 & 0.757 & $0.497,1.151$ & 0.193 & 1.009 & $0.347,2.935$ & 0.987 \\
\hline Diet control & 1.489 & $0.506,4.382$ & 0.470 & 1.277 & $0.667,2.447$ & 0.460 & 1.048 & $0.627,1.752$ & 0.857 & 4.464 & $1.265,15.750$ & 0.020 \\
\hline Daily staple food intake & 2.341 & $0.514,10.669$ & 0.272 & 1.329 & $0.715,2.469$ & 0.368 & 0.987 & $0.669,1.454$ & 0.946 & / & / & / \\
\hline Physical activity & 1.694 & $0.328,8.758$ & 0.530 & 0.737 & $0.205,2.651$ & 0.640 & 1.935 & $0.728,5.139$ & 0.186 & 2.994 & $0.508,17.639$ & 0.226 \\
\hline
\end{tabular}


and medication with CHD, lipid profiles and end events.

\section{Abbreviations}

CHD: Coronary heart disease; PCl: Percutaneous coronary intervention; TC: Total cholesterol; TG: Triglyceride; LDL-C: Low-density lipoprotein cholesterol; HDL-C: High-density lipoprotein cholesterol; CCU: Cardiac intensive care unit; NCEP: National Cholesterol Education Program; NCEP-ATP III: National Cholesterol Education Program (Adult Treatment Panel III); DM: Diabetes mellitus; FPG: Fasting plasma glucose; $2 \mathrm{hPG}$ : $2 \mathrm{~h}$ postprandial plasma; SBP: Systolic blood pressure; DBP: Diastolic blood pressure; BMI: Body mass index; OR: Odds ratios

\section{Acknowledgements}

The authors are grateful to the staff in the participating research.

\section{Authors' contributions}

Study design: Data analysis/interpretation: All authors. The revision and review of the manuscript: All authors. Approval of final draft for submission: All authors. All authors read and approved the final manuscript.

\section{Funding}

No funding was supported.

\section{Availability of data and materials}

The datasets used or analysed during the current study are available as supplementary Tables.

\section{Ethics approval and consent to participate}

The study was approved by the first affiliated hospital of Jinan University Ethics Committee (Ethical Approval Number: 20190812-033; Approval date: 12th, August 2019.).

\section{Consent for publication}

Not applicable.

\section{Competing interests}

The authors declare that they have no competing interests.

\section{Author details}

'Department of Cardiology, The First Affiliated Hospital of Jinan University, 613 Huangpu Da Dao Xi, Guangzhou 510630, Guangdong, China. ${ }^{2}$ Department of Transitional care, The First Affiliated Hospital of Jinan University, 613 Huangpu Da Dao Xi, Guangzhou 510630, Guangdong, China.

Received: 26 September 2019 Accepted: 30 June 2020

Published online: 06 July 2020

\section{References}

1. GBD 2017 Causes of Death Collaborators. Global, regional, and national agesex-specific mortality for 282 causes of death in 195 countries and territories, 1980-2017: a systematic analysis for the Global Burden of Disease Study 2017. Lancet. 2018;392:1736-88

2. Collins DR, Tompson AC, Onakpoya U, Roberts N, Ward AM, Heneghan CJ. Global cardiovascular risk assessment in the primary prevention of cardiovascular disease in adults: systematic review of systematic review. BM Open. 2017:7:e013650.

3. American Heart Association: Cholesterol statistics. http://www. americanheart.org/presenter.jhtml?identifier=536. Accessed 20 Oct 2016

4. Wen Y, Leake DS. Low density lipoprotein undergoes oxidation within lysosomes in cells. Circ Res. 2007:100:1337-43.

5. Lee JS, Chang PY, Zhang Y, Kizer JR, Best LG, Howard BV. Triglyceride and HDL-C dyslipidemia and risks of coronary heart disease and ischemic stroke by glycemic Dysregulation status: the strong heart study. Diabetes Care. 2017:40:529-37.

6. Bartlett J, Predazzi IM, Williams SM, Bush WS, Kim Y, Havas S, Toth PP, Fazio S, Miller M. Is isolated low high-density lipoprotein cholesterol a cardiovascular disease risk factor? New insights from the Framingham offspring study. Circ Cardiovasc Qual Outcomes. 2016;9:206-12.

7. He J, Gu D, Reynolds K. Wu X, Muntner P, Zhao J, Chen J, Liu D, Mo J, Whelton PK, et al. Serum total and lipoprotein cholesterol levels and awareness, treatment, and control of hypercholesterolemia in China. Circulation. 2004:110:405-11.

8. $\quad$ Yang W, Xiao J, Yang Z, Ji L, Jia W, Weng J, Lu J, Shan Z, Liu J, Tian H, et al. Serum lipids and lipoproteins in Chinese men and women. Circulation. 2012;125:2212-21.

9. Cholesterol Treatment Trialists' (CTT) Collaborators, Mihaylova B, Emberson J, Blackwell L, Keech A, Simes J, Barnes EH, Voysey M, Gray A, Collins R, et al. The effects of lowering LDL-C cholesterol with statin therapy in people at low risk of vascular disease: meta-analysis of individual data from 27 randomised trials. Lancet. 2012;380:581-90.

10. Harris MA, Ferguson TS, Boyne MS, Figueroa JP. High prevalence of dyslipidemia among primary care patients with hypertension and diabetes in Jamaica. Arch Med Sci Atheroscler Dis. 2017;2:e61-7.

11. Spannella F, Giulietti F, Di Pentima C, Sarzani R. Prevalence and control of dyslipidemia in patients referred for high blood pressure: the disregarded "double-trouble" lipid profile in overweight/obese. Adv Ther. 2019;36:1426-37.

12. Zhang M, Deng Q, Wang L, Huang Z, Zhou M, Li Y, Zhao Z, Zhang Y, Wang $L$. Prevalence of dyslipidemia and achievement of low-density lipoprotein cholesterol targets in Chinese adults: a nationally representative survey of 163,641 adults. Int J Cardiol. 2018:260:196-203.

13. Li YH, Li Y, Davis CE, Chen Z, Tao S, Folsom AR, Bachorik P, Stamler J, Abernathy JR. Serum cholesterol changes from 1983-1984 to 1993-1994 in the People's republic of China. Nutr Metab Cardiovasc Dis. 2002;12:118-26.

14. Li LM, Rao KQ, Kong LZ, Yao CH, Xiang HD, Zhai FY, Ma GS, Yang XG. Chinese resident nutrition and health survey technology executive team. The 2002 China National Nutrition and health survey. Chin J Epidemiol. 2005;26:474-84 (in Chinese).

15. Joint Committee Issued Chinese Guideline for the Management of Dyslipidemia in Adults. Chinese guideline for the management of dyslipidemia in adults. Chinese J Cardiol. 2016;44:833-53 in Chinese

16. Expert Panel on Detection, Evaluation, and Treatment of High Blood Cholesterol in Adults. Executive summary of the third report of the national cholesterol education program (NCEP) expert panel on detection, evaluation, and treatment of high blood cholesterol in adults (adult treatment panel III). JAMA. 2011:285:2486-97.

17. Alberti $K G$, Zimmet PZ. Definition, diagnosis and classification of diabetes mellitus and its complications. Part1:diagnosis and classification of diabetes mellitus provisional report of a WHO consultation. Diabet Med. 1998;15:539-53.

18. Giovino GA, Mirza SA, Samet JM, Gupta PC, Jarvis MJ, Bhala N, Peto R, Zatonski W, Hsia J, Morton J, et al. Tobacco use in 3 billion individuals from 16 countries: an analysis of nationally representative cross-sectional household surveys. Lancet. 2012;380:668-79.

19. Carroll MD, Kit BK, Lacher DA, Shero ST, Mussolino ME. Trends in lipids and lipoproteins in US adults, 1988-2010. JAMA. 2012:308:1545-54.

20. Arai H, Yamamoto A, Matsuzawa Y, Saito Y, Yamada N, Oikawa S, Mabuchi $\mathrm{H}$, Teramoto T, Sasaki J, Nakaya N, et al. Prevalence of metabolic syndrome in the general Japanese population in 2000. J Atheroscler Thromb 2006;13: 202-208.

21. Lee $\mathrm{YH}$, Lee SG, Lee MH, Kim JH, Lee BW, Kang ES, Lee HC, Cha BS. Serum cholesterol concentration and prevalence, awareness, treatment, and control of high low-density lipoprotein cholesterol in the Korea National Health and nutrition examination surveys 2008-2010: beyond the tip of the iceberg. J Am Heart Assoc. 2014;3:e000650.

22. Liu X, Y U S, Mao Z, Li Y, Zhang H, Yang K, Zhang H, Liu R, Qian X, Li L, et al. Dyslipidemia prevalence, awareness, treatment, control and risk factors in Chinese rural population: the Henan rural cohort study. Lipids Health Dis. 2018:17:119.

23. Yuan X, Ni W, Wang R, Chi H, Sun Y, Lv D, Liu P, Xu J. 6-year trends in lipids among adults in Shenzhen, China. J Public Health (Oxf). 2019; pii: fdz113.

24. Jain RB, Ducatman A. Association between smoking and lipid/lipoprotein concentrations among US adults aged $\geq 20$ years. J Circ Biomark. 2018;7: 1849454418779310

\section{Publisher's Note}

Springer Nature remains neutral with regard to jurisdictional claims in published maps and institutional affiliations. 